\title{
Desenvolvimento de Equipamentos para o Mapeamento de Áreas INFESTADAS POR MACRÓFITAS AQUÁTICAS IMERSAS ${ }^{1}$
}

\author{
Development of Equipments for Mapping Areas Infested with Submerged Aquatic Macrophytes
}

\author{
CORREA, M.R. ${ }^{2}$, BRAVIN, L.F.N. ${ }^{3}$, VELINI, E.D. ${ }^{4}$, BAIO, F.H.R. ${ }^{5}$ e GALO, M.L.B.T. ${ }^{6}$
}

\begin{abstract}
RESUMO - Foi desenvolvido um conjunto de equipamentos com o objetivo de mapear as áreas infestadas por macrófitas aquáticas, auxiliando operações de manejo mecânico, as quais são realizadas por uma colhedora desenvolvida especificamente para essa finalidade. O conjunto de equipamentos foi constituído por um GPS com programa de correção diferencial, acoplado a um palmtop, um sistema com dois teclados ligados em dataloggers e um transdutor de deslocamento linear LT. O GPS, através do palmtop, proporcionava o mapeamento da área de deslocamento, auxiliando o operador na movimentação da máquina, otimizando a operação e evitando, dessa forma, a sobreposição das faixas de coleta na área a ser manejada. Um dos teclados monitorava a movimentação e operação da colhedora, além da presença de obstáculos, como tocos e bancos de areia, enquanto o outro gerava dados sobre a presença de determinada espécie de planta, como E. densa, E. najas e C. demersum, além do nível de infestação destas plantas. O transdutor, instalado na plataforma frontal da colhedora, se movimentava linearmente, gerando informações sobre a profundidade da coleta realizada. Dessa forma, pôde-se observar que o desenvolvimento desse conjunto de equipamentos foi de grande utilidade e auxiliou a operação de controle mecânico de áreas infestadas por macrófitas aquáticas imersas, possibilitando, assim, o planejamento de operações de manejo e controle subseqüentes.
\end{abstract}

Palavras-chave: plantas aquáticas, controle mecânico, GPS.

\begin{abstract}
An equipment kit was developed to map areas infested with aquatic macrophytes providing support to mechanical control operations performed by a harvester particularly developed for this purpose. The equipment kit consisted of a GPS with differential correction program connected to a palmtop, a system with two keyboards coupled to dataloggers, and an LT, linear displacement transducer. Through the palmtop, the GPS provided a mapping of the displacement area, helping the machine operator move the harvester, optimizing the operation and thus preventing overlapping of the collecting areas. One of the keyboards monitored the machine movement and operation, as well as the presence of obstacles, such as stumps or sand benches. The other keyboard generated data on the presence of particular plants, such as $\boldsymbol{E}$. densa, $\boldsymbol{E}$. najas and $\boldsymbol{C}$. demersum, as well as their infestation level. The transducer installed in the frontal platform of the machine moved linearly, generating data on harvest depth. It was shown that the development of this equipment kit was advantageous and helped the mechanical control operation in the areas infested with submerged aquatic macrophytes, thus allowing to plan subsequent management operations and control.
\end{abstract}

Key words: macrophytes, mechanical control, GPS.

1 Recebido para publicação em 17.11.2004 e na forma revisada em 5.4.2005.

2 Eng.-Agr., M.S., Programa de Pós-Graduação em Agricultura, Departamento de Produção Vegetal/Agricultura, FCA/UNESP, Caixa Postal 237, 18603-970 Botucatu-SP, <mrcorrea@fca.unesp.br $>$; ${ }^{3}$ Eng. Naval, M.S., Prof. da Faculdade de Tecnologia de Botucatu - FATEC, 18606-855 Botucatu-SP. ${ }^{4}$ Prof. Dr., Departamento de Produção Vegetal/Agricultura, FCA/UNESP, BotucatuSP; ${ }^{5}$ Eng.-Agr., M.S., Dep. de Engenharia Rural, FCA/UNESP, Botucatu-SP; ${ }^{6}$ Professora Dra., Dep. de Cartografia da Faculdade de Ciência e Tecnologia, FCT/UNESP, Caixa Postal 467, 19060-900 Presidente Prudente-SP. 


\section{INTRODUÇÃO}

A presença de altas infestações de plantas aquáticas em reservatórios de hidrelétricas vem ocasionando sérios prejuízos para as empresas geradoras de energia, em razão do deslocamento de massas de plantas, ocasionando o entupimento das tomadas de água das turbinas, paralisando a geração de energia elétrica (Pompêo, 1999; Velini, 2000; Pompêo \& Moschini-Carlos, 2003).

Segundo Braga (2002), a construção de barragens em rios de bacias hidrográficas do Brasil causa profundas modificações nos componentes da fauna e flora local. Além disso, a introdução de espécies exóticas contribui para o desequilíbrio da estabilidade que poderá ocorrer após o barramento.

Alguns fatores, como turbidez, composição do sedimento e disponibilidade de nutrientes, podem induzir o aparecimento de condições adequadas ao desenvolvimento e rápida propagação de macrófitas aquáticas (Bianchini Junior, 2003). A vegetação aquática passa a ser encarada como daninha quando seu crescimento acentuado causa problemas para a utilização dos ecossistemas, surgindo a partir desse momento a necessidade de aplicação de métodos de controle ou manejo (Pitelli, 1998).

Em contraste com os prejuízos já constatados e ocasionados por essa vegetação aquática, inexiste no Brasil uma legislação específica envolvendo o monitoramento e controle de plantas aquáticas (Carvalho et al., 2003). Conforme relatado por Cavenaghi et al. (2002), o desenvolvimento de métodos de controle dessas espécies faz-se necessário, principalmente pela escassez de informações referentes a essas técnicas no país.

Algumas técnicas de controle biológico, utilizando peixes como agente predador destas macrófitas e com resultados satisfatórios, são citadas por Edwards (1974), Catarino et al. (1997) e Myiazaki \& Pitelli (2003). O uso de herbicidas como prática de controle também já foi testado, sendo observados resultados consideravelmente seguros e satisfatórios. Estudos realizados por Martins et al. (2002), Neves et al. (2002), Marcondes et al. (2003) e Negrisoli et al. (2003), por exemplo, podem comprovar a eficiência deste método de controle.
De acordo com Velini (2000), o controle mecânico pode ser considerado um método vantajoso em relação aos citados anteriormente, pelo fato de não liberar compostos químicos ou tóxicos na água, além de atuar de modo pontual nas áreas de maiores infestações. No entanto, estudos que analisam a eficiência e o desempenho desta técnica praticamente inexistem no Brasil, com destaque para trabalho realizado por Antuniassi et al. (2002), os quais avaliaram a capacidade operacional e econômica deste método de controle.

A tecnologia do GPS (Sistema de Posicionamento Global) e do DGPS (Sistema de Posicionamento Global, Diferencial) consiste na obtenção das coordenadas de um ponto da superficie terrestre mediante a captação de sinais de satélites. As coordenadas assim obtidas podem ser utilizadas para uma infinidade de aplicações, que vão desde a navegação, aérea ou marítima, passando por diversas atividades agrícolas, como agricultura de precisão. Assim, o desenvolvimento de sensores, atuadores e softwares que venham a ser empregados nas máquinas com orientação por GPS oferece uma grande oportunidade de negócios, desenvolvimento de tecnologia e criação de empregos (Araújo, 2004).

Com o propósito de otimizar operações de manejo e controle de macrófitas aquáticas imersas, foi desenvolvido um conjunto de equipamentos que pudesse auxiliar operadores no controle mecânico dessas espécies de plantas, por meio de um mapeamento de áreas infestadas e controladas.

\section{MATERIAL E MÉTODOS}

O presente trabalho foi realizado no reservatório de Jupiá, pertencente à Companhia Energética de São Paulo - CESP, utilizando-se uma colhedora de plantas aquáticas desenvolvida especificamente para essa finalidade (Figura 1). Foi desenvolvido um conjunto de equipamentos com os objetivos de auxiliar e fornecer informações aos operadores da máquina e técnicos envolvidos, por meio de mapeamento das áreas infestadas durante as operações de controle mecânico de macrófitas aquáticas.

O conjunto de equipamentos foi instalado na colhedora e era constituído por um GPS GcIQ Satloc, com programa de correção 
diferencial, acoplado a um palmtop, um sistema com dois teclados ligados em dataloggers, marca Novus, e um transdutor de deslocamento linear LT, marca Gefran (Figura 2).

O GPS, através do palmtop, proporcionava a visualização do deslocamento e mapeamento da área, auxiliando o operador na movimentação da máquina, otimizando a operação e evitando, dessa forma, a sobreposição das faixas de coleta na área manejada.
Um dos teclados monitorava a movimentação e operação da colhedora (parada, navegando, coletando ou descartando), além da presença de obstáculos, como tocos e bancos de areia. Da mesma forma, o outro teclado gerava dados sobre a presença de determinada espécie de planta aquática - no caso, Egeria densa, E. najas e Ceratophyllum demersum-, bem como o nivel de infestação local (alta, média, baixa ou nenhuma).

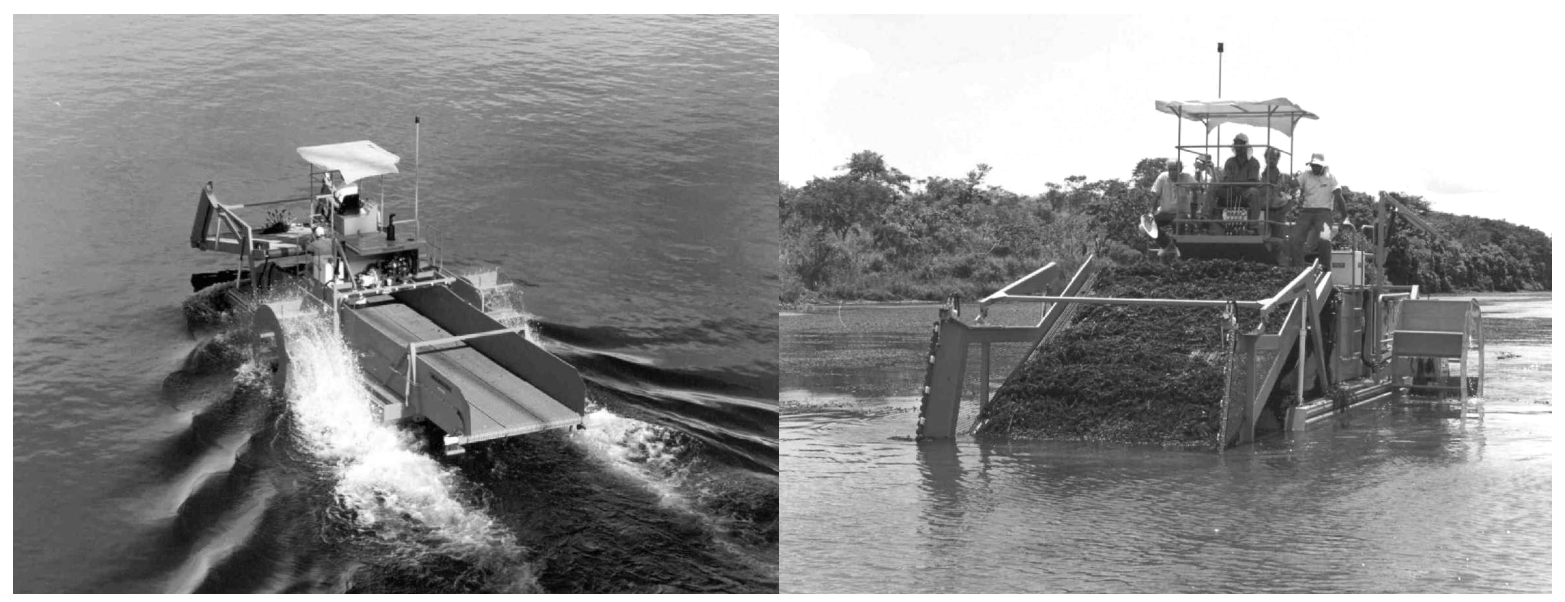

Figura 1 - Colhedora de plantas aquáticas, navegando e operando, no reservatório de Jupiá.

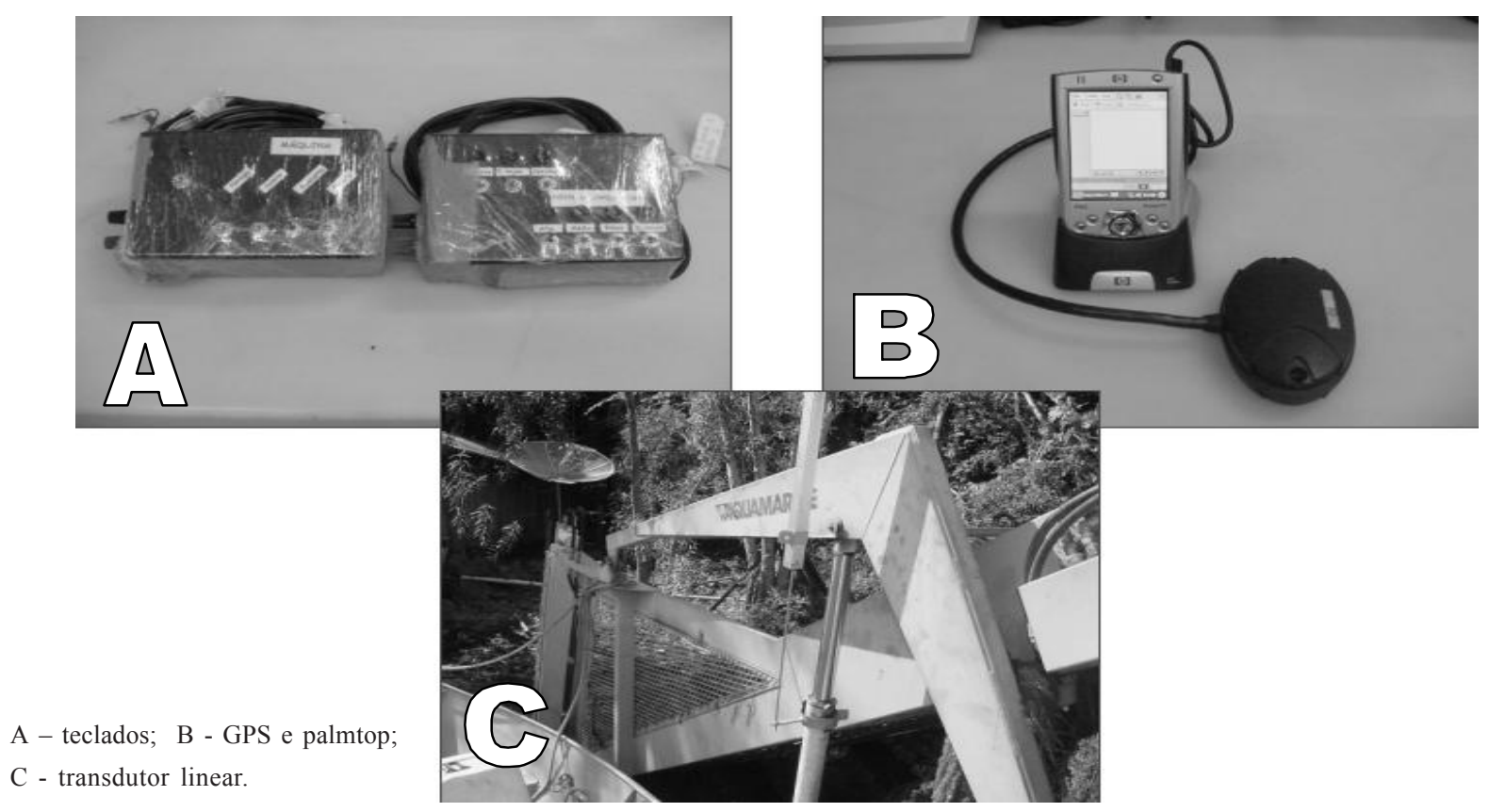

Figura 2 - Detalhamento dos equipamentos utilizados para monitoramento da infestação de plantas aquáticas no reservatório de Jupiá. 
O transdutor LT, instalado na plataforma frontal da colhedora, se deslocava linearmente conforme a movimentação do pistão da plataforma, gerando informações sobre a profundidade da coleta realizada, variando de 0 a $1,80 \mathrm{~m}$.

O conjunto de equipamentos foi programado de tal forma que gerasse e fornecesse dados a cada 2 segundos ou 2 metros (condição que primeiro ocorresse).

\section{RESULTADOS E DISCUSSÃO}

O desenvolvimento do conjunto de equipamentos proporcionou uma base de dados relativa a uma determinada área do reservatório de Jupiá, relacionando todos os parâmetros de movimentação e operação da colhedora, espécies de macrófitas presentes, niveis de infestação e localização geográfica das faixas de infestações e dos obstáculos presentes no local.

O conjunto de equipamentos auxiliou com sucesso a operação de controle mecânico nas áreas infestadas por macrófitas aquáticas imersas do presente reservatório, proporcionando a confecção de mapas com coordenadas geográficas (Figura 3) e apresentando a localização exata da área manejada, orientando, assim, o operador a não sobrepor as faixas de coleta de plantas.

O deslocamento e a operação da máquina podem ser observados na Figura 4. Nota-se um grande período em que a colhedora esteve operando (coletando plantas), estimando o tempo de coleta e gasto com descarregamento da máquina na margem. Dessa forma, pode se estabelecer o tempo gasto em uma operação de controle, maximizando as informações de avaliação operacional desse método.

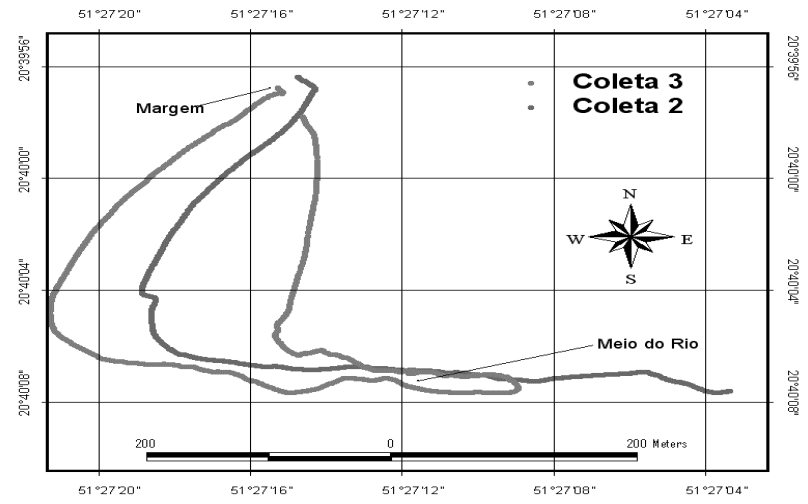

Figura 3 - Mapeamento e georreferenciamento da movimentação e operação da colhedora, na área do reservatório de Jupiá.

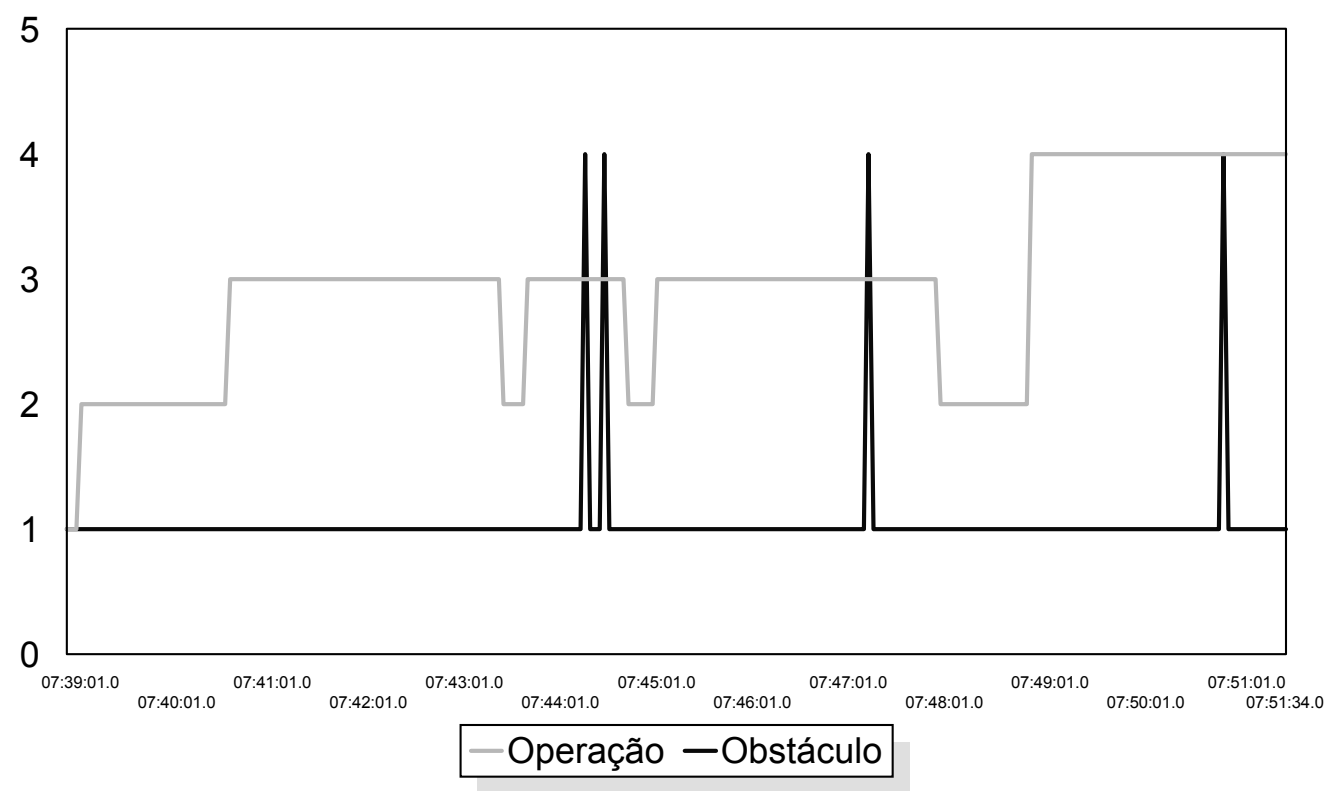

1 - parada; 2 - navegando; 3 - coletando; 4 - descartando.

Figura 4 - Representação esquemática da movimentação da colhedora e presença de obstáculos na área amostrada. 
A presença de obstáculos, representada pelos picos no gráfico da Figura 4, guia, através de correlação com dados de coordenadas do GPS, a localização exata do referido obstáculo, sejam tocos ou bancos de areia. Complementando as informações, em programas de manejo subseqüentes e de posse do mapeamento da área, pode-se evitar a passagem sobre este obstáculo, evitando a perda da capacidade operacional e possível dano em peças da colhedora.

As diferentes espécies da área estão representadas na Figura 5. Nota-se que a presença de Egeria densa foi predominante em todo o período de avaliação. Observa-se também a presença de alguns focos de infestação de Egeria najas e Ceratophyllum demersum. Entretanto, a infestação mista com duas ou três espécies também foi significativa em boa parte da avaliação.

O nível de infestação apresentado na área escolhida e observado na Figura 6 indica a predominância de niveis de baixa e média infestação de macrófitas. Em parte da coleta, a área foi considerada de alta infestação, representada pela grande quantidade de biomassa recolhida na plataforma da máquina. Em alguns pontos, foi notada a ausência de infestação, o que pode ter sido ocasionado por falha populacional de plantas naquele local.

A profundidade de coleta ocorrida durante a operação de manejo está representada na Figura 7 , na qual se pode observar que, na maior parte da avaliação, a colhedora operou a uma profundidade média de $1,0 \mathrm{~m}$, oscilando de 0,6 a 1,5 m. Esta profundidade foi considerada satisfatória para o controle mecânico, uma vez que em maiores profundidades a plataforma frontal fica inclinada numa posição vertical, dificultando a entrada de plantas na máquina, minimizando dessa maneira o rendimento operacional.

As informações geradas possibilitam também o planejamento de operações de manejo e controle subseqüentes, pois, dessa forma, pode-se conhecer o nivel de infestação de diferentes espécies, em áreas pontuais do reservatório, auxiliando estratégias de controle dessas espécies de plantas aquáticas.

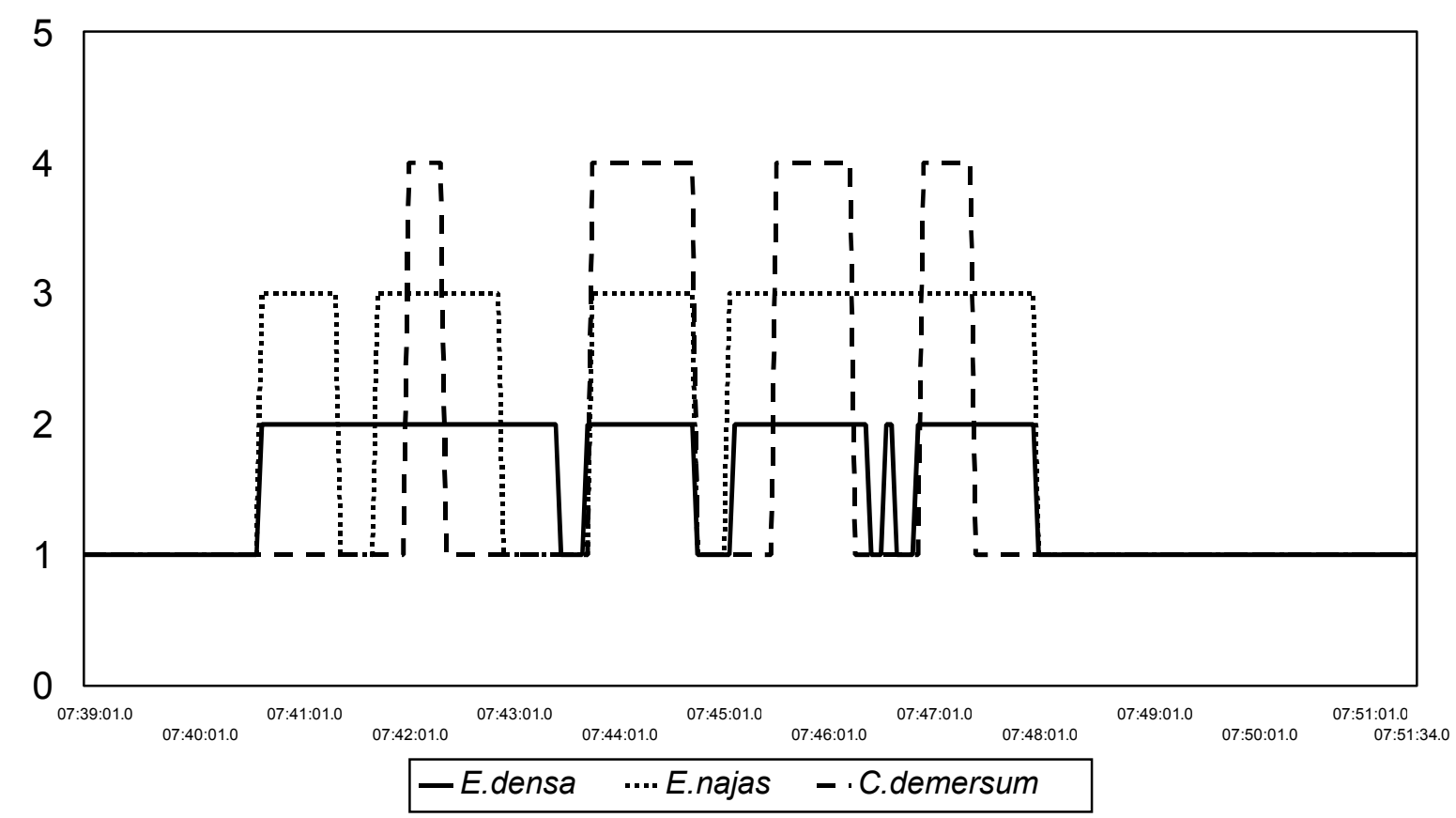

1 - ausência; 2 - Egeria densa; 3 - Egeria najas; 4 - Ceratophyllum demersum.

Figura 5 - Representação da presença de espécies de macrófitas na área amostrada. 


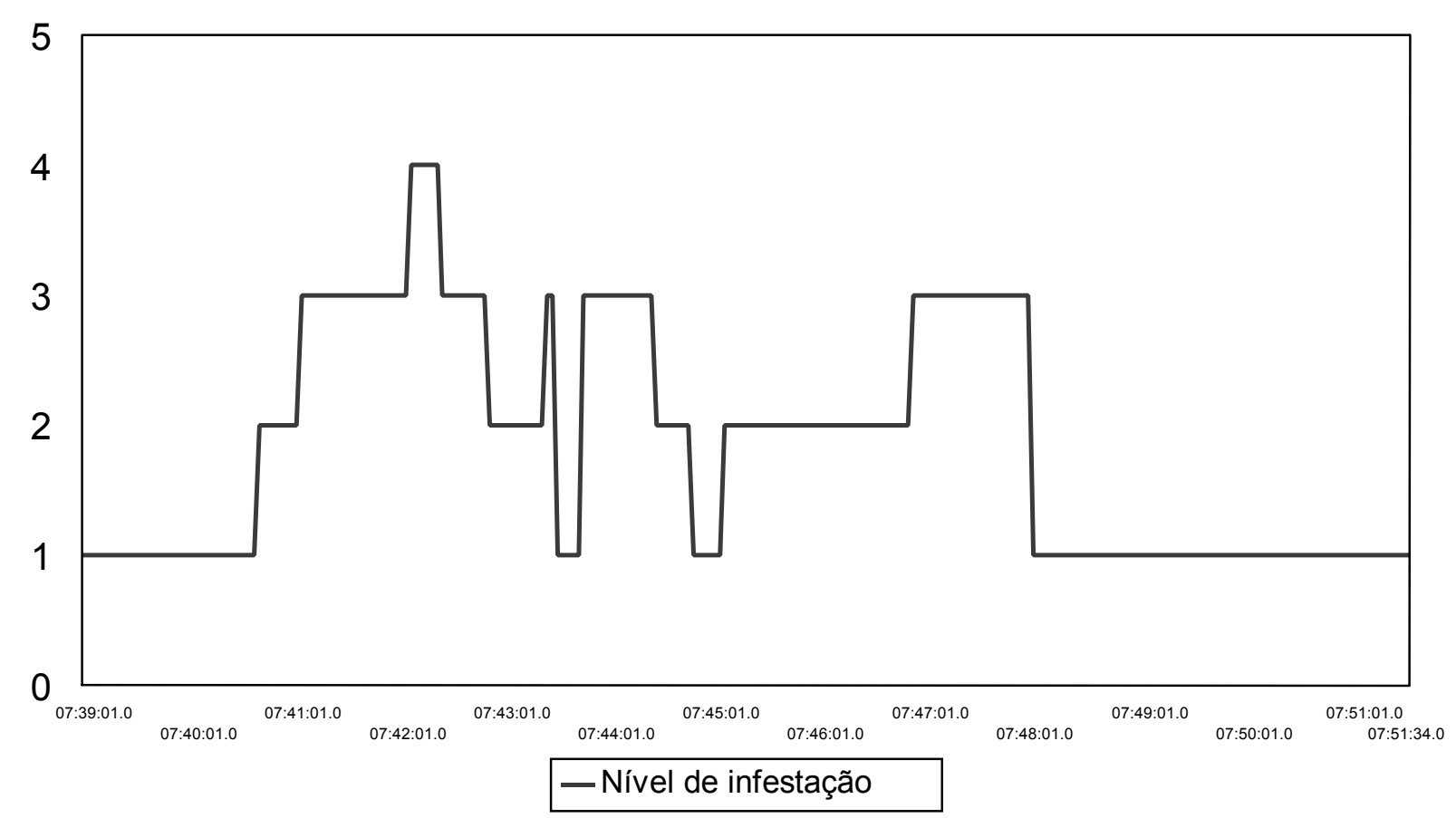

1 - nenhuma; 2 - baixa; 3 - média; 4 - alta.

Figura 6 - Representação esquemática do nível de infestação da área amostrada.

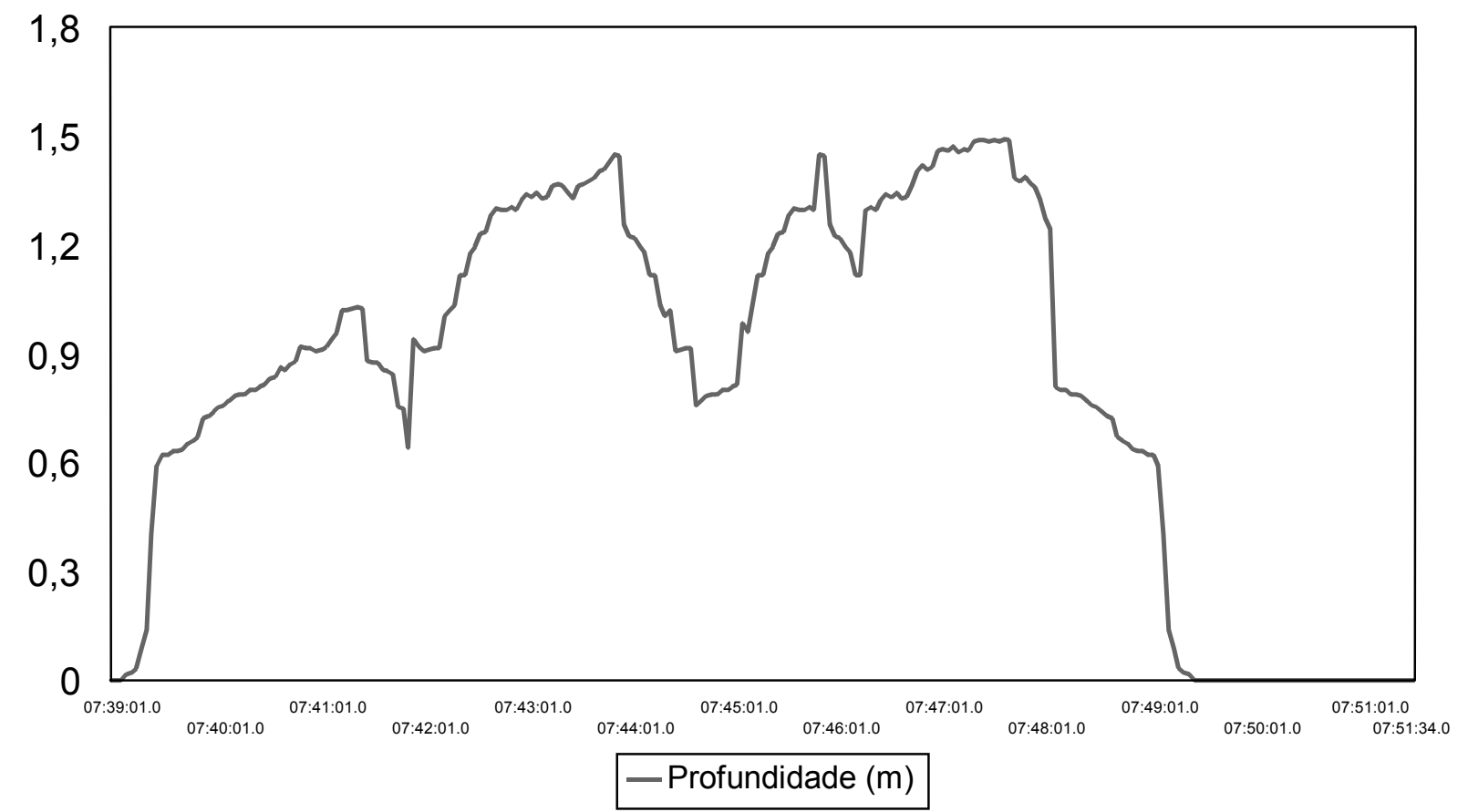

Figura 7 - Representação gráfica da profundidade de coleta $(\mathrm{m})$ da plataforma frontal da colhedora de plantas aquáticas no reservatório de Jupiá. 


\section{AGRADECIMENTOS}

À Companhia Energética de São Paulo CESP, pelo suporte técnico durante a realização deste trabalho.

\section{LITERATURA CITADA}

ANTUNIASSI, U. R.; VELINI, E. D.; MARTINS, D. Remoção mecânica de plantas aquáticas: análise econômica e operacional. Planta Daninha, v. 20, p. 35-43, 2002. (Edição especial)

ARAÚJO, E. C. Agricultura de precisão. Agrotec Tecnologia Agrícola e Industrial Ltda. Disponível em: $<$ http://www.agrotec.etc.br/referencia/agrprec/agrprec.html $>$. Acesso em: 20 out. 2004.

BIANCHINI JUNIOR, I. Modelos de crescimento e decomposição de macrófitas aquáticas. In: THOMAZ, S. M.; BINI, L. M. (Eds.) Ecologia e manejo de macrófitas aquáticas. Maringá: EDUEM, 2003. p. 85-126.

BRAGA, F. M. S. Estudo de recifes artificiais como atratores de peixes no reservatório de Volta Grande, Rio Grande (MG-SP). Acta Limn. Bras., v. 14, n. 2, p. 65-76, 2002.

CARVALHO, F. T. et al. Plantas aquáticas e nível de infestação das espécies presentes no reservatório de Barra Bonita, no rio Tietê. Planta Daninha, v. 21, p.15-19, 2003. (Edição especial)

CATARINO, L. F.; FERREIRA, M. T.; MOREIRA, I. S. Preferences of grass carp for macrophytes in Iberian drainage channels. J. Aquatic Plant Manag., v. 36, p. 79-83, 1997.

CAVENAGHI, A. L. et al. Determinação de resíduo do herbicida fluridone em peixe. Planta Daninha, v. 20, p. 57-61, 2002. (Edição especial)
EDWARDS, D. J. Weeds preference and growth of young grass carp in New Zealand. New Zealand J. Marine Fresh. Res., v. 8, n. 2, p. 341-350, 1974.

MARCONDES, D. A. S. et al. Eficiência de fluridone no controle de plantas aquáticas submersas no reservatório de Jupiá. Planta Daninha, v. 21, p. 69-77, 2003. (Edição especial)

MARTINS, D. et al. Controle químico de Pistia stratiotes, Eichhornia crassipes e Salvinia molesta em caixas d'água. Planta Daninha, v. 20, p. 83-88, 2002. (Edição especial)

MIYAZAKI, D. M. Y.; PITELLI, R. A. Estudo do potencial do pacu (Piaractus mesopotamicus) como agente de controle biológico de Egeria densa, E. najas e Ceratophyllum demersum. Planta Daninha, v. 21, p. 53-59, 2003. (Edição especial)

NEGRISOLI, E. et al. Uso de diferentes herbicidas no controle de Myriophyllum aquaticum. Planta Daninha, v. 21, p. 89-92, 2003. (Edição especial)

NEVES, T.; FOLONI, L. L.; PITELLI, R. A. Controle químico do aguapé (Eichhornia crassipes). Planta Daninha, v. 20, p. 89-97, 2002. (Edição especial)

PITELLI, R. A. Macrófitas aquáticas no Brasil, na condição de problemáticas. In: WORKSHOP SOBRE CONTROLE DE PLANTAS AQUÁTICAS, 1998, Brasília. Anais... Brasília: IBAMA, 1998. p. 32-35.

POMPÊO, M. L. M. Perspectivas da limnologia no Brasil. São Luis: União, 1999. 191 p.

POMPÊO, M. L. M.; MOSCHINI-CARLOS, V. Macrófitas aquáticas e perifiton: aspectos ecológicos e metodológicos. São Carlos: RiMa, 2003. 134 p.

VELINI, E. D. Controle de plantas daninhas aquáticas. In: CONGRESSO BRASILEIRO DA CIÊNCIA DAS PLANTAS DANINHAS, 22., 2000, Foz do Iguaçu. Palestras... Foz do Iguaçu: SBCPD, 2000. p. 137-47. 